\title{
PROCESS AND PRODUCT OPTIMIZATION IN THE ARTISANAL PRODUCTION OF SICILIAN COFFE GELATO
}

\author{
Diego Planeta $^{1 凶,}$ Luciano Cinquanta $^{1}$, Onofrio Corona $^{1}$, Aldo Todaro $^{1}$, Liviu Giurgiulescu ${ }^{2}$, \\ Federica Greco ${ }^{3}$, Franco Grisafi ${ }^{3}$ \\ ${ }^{1}$ Dipartimento di Scienze Agrarie, Alimentari e Forestali - Università degli Studi di Palermo, Viale delle \\ Scienze 13, 90128 Palermo, Italy. \\ ${ }^{2}$ North Universitary Center of Baia Mare, Technical University of Cluj Napoca, Chemistry-Biology Department \\ ${ }^{3}$ Dipartimento di Ingegneria - Università degli Studi di Palermo, Viale delle Scienze 62, 90128 Palermo, Italy. \\ $\triangle$ diego.planeta@unipa.it \\ https://doi.org/10.34302/crpjfst/2020.12.4.2 \\ Article history: \\ Received: \\ 8 March 2020 \\ Accepted: \\ 10 October 2020 \\ Keywords: \\ Artisan gelato \\ Coffee; \\ Gelato; \\ Granita; \\ Sorbetto.

\begin{abstract}
The production of artisan gelato has always been a very important sector for the Italian economy, the aim of this work is to highlight the peculiarity of production in Sicily, in synergy with a young economic reality and the production reality that is expanding Gelateria Cappadonia, Caffè Morettino Srl Palermo and the academic world.

The aim of this research is to solve the color change during the production of artisan coffee gelato.
\end{abstract}

\section{Introduction}

The artisanal production of gelato is widespread in Italy and in Sicily some companies represent an excellence in the sector. The production methods of these companies, in most cases have changed a lot over time, being able to take advantage of a technological development that is present in the sector, which has safe and reproducible food products for its organoleptic characteristics. This prompted the work of the gelato masters for the development of new recipes and formulas of gelato and various sorbets. In fact, production is not always essential due to problems or requires some form of optimization (process or product) to better meet market needs. In these cases, the approach to solving problems is often empirical, almost always based on the experience of the master gelato maker. The activity carried out in this experimental work stems from the need to find a solution to a problem of "coloring" of a type of gelato with an approach that was not simply empirical but also made use of a scientific basis. Gelato is a complex food which in the frozen state consists of ice crystals, air and fat droplets dispersed in an aqueous phase (called serum) containing polysaccharides such as galactomannans, carrageenan (food gelatin), cellulosics, sugars (sucrose and lactose), proteins and minerals (especially calcium, but also sodium and potassium) (Soukoulis et al., 2014). The term "gelato" includes a wide range of frozen desserts (Clarke, 2005) and its composition varies depending on the country and the demand of the country's consumer. The main families are: creams, sorbets and granitas. The creams are in turn divided into egg creams and milk creams, depending on the presence or absence of the first ingredient that has the emulsifying function. For this type of gelato, the pasteurization process is necessary in order to 
remove the bacterial load present. The white cream family includes, among others, vanilla, cinnamon and coffee gelato.The parameters established for a cream gelato set the amount of water around $64 \%$ of the total, while the rest, $36 \%$, is reserved for the dry extract, always providing a margin of variation determined by the characteristics of each gelato (Corvitto, 2005). The sorbet means a frozen product based on water, sugars and neutral stabilizer. A cause of the lack of raw materials and milk powder, sorbets retain all the genuine flavor of the fruit or raw material used and for the reason given and refreshing. Generally, the sugar content in sorbets is twice that of gelato. Compared to creams, sorbets have a higher fruit content and a thicker consistency which therefore causes a greater feeling of cold on the palate (Douglas, Hartel, 2013). The peculiarity of this type of product is the unnecessary pasteurization. This is because almost all fruit has a $\mathrm{pH}<4$.6, which indicates the absence of bacterial load means pathogenic, as it does not survive in such conditions. For sorbets the amount of water is about $70 \%$, while the dry amount is about $30 \%$. Granitas represent ice water containing sugar and flavors. It is similar to the sorbet, with the difference in communication in this case there is the complete absence of neutral. Another difference lies in the slow agitation which, for the reason, causes a rougher consistency caused by the larger ice crystals. (Douglas, Hartel, 2013). The ice crystals must be very fine, noticeable on the tongue and easily melt in the mouth. Generally the percentage of sugar is between 14 and $24 \%$. The sugar most used in the preparation of granite is sucrose. The aim of this research is to solve the color change during the production of artisan coffee gelato.

\section{Materials and methods}

The experimental tests were carried out at the Cappadonia Company's artisan factory in Cerda, in the province of Palermo. The main functions of the sugar inside the gelato are to give sweetness, increase the viscosity of the final product (thus improving the structure) and lower the freezing point. The higher the sugar content, therefore, the lower the ice content, therefore the softer the gelato will be. Neutrals, represented by emulsifiers and stabilizers, have a very important role for the final structure and for the quality of the gelato. The goal for the production of a high quality gelato is that the water and fats are eliminated in such a way as to prevent the two phases from returning to two separate phases. The liquid phase in gelato is largely composed of water, its quantity is about $60 \%$. It plays a fundamental role for the production of gelato, without it, in fact it would not be possible. The gas phase is represented by air. The air incorporated in the gelato causes it to be lighter, has a lower specific heat capacity (both felt in the mouth as less "cold") and is also creamier. The increase in the volume of an gelato mix, defined by the incorporated air, is called overrun (Corvitto, 2005). A method for determining the optimal amount of air for gelato is described by the following equation 1 :

$$
\text { overrun }=\frac{\text { density mix }- \text { density ice cream }}{\text { density ice cream }} \times 100
$$

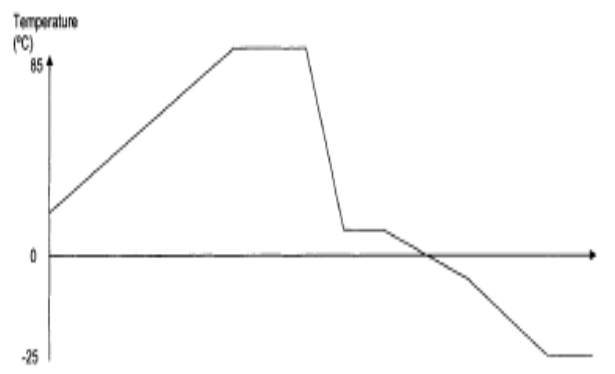

A

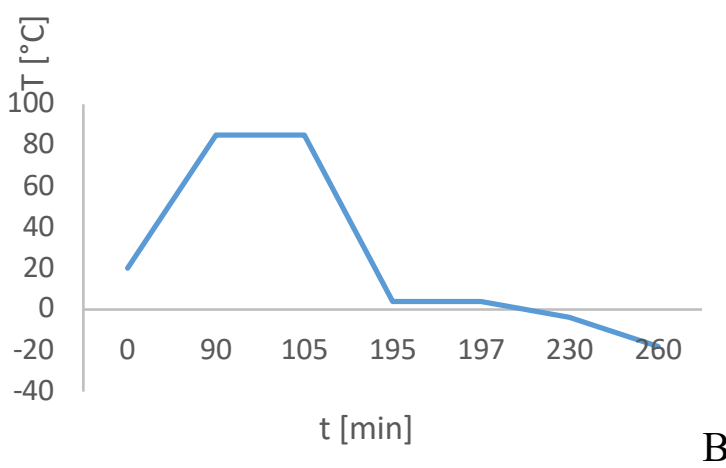

Figure 1. A-B (A) Temperature profile during the gelato production process (Clarke, 2004) and 
(B) temperature profile during the experimental gelato production process.

The production process involves a precise weighing, before the gelato production process. This occurs through the succession of different phases: mixing, pasteurization and homogenization, maturation, freezing, temperature reduction, conservation and finally exposure. Due to these multiple steps, the mixture follows a variable temperature profile. In fact, it first grows from room temperature up to $85^{\circ} \mathrm{C}$, during the pasteurization process, then decreases down to $-25^{\circ} \mathrm{C}$ in the following steps (Fig. 1).

It is important to highlight the process of reducing the temperature since during the process the process of crystallization of the water takes place. It occurs in four stages: lowering the temperature, nucleation, growth and recrystallization. Crystallization of the solvent occurs when the temperature drops below the freezing temperature of the mixture. As we know, the freezing temperature of the water is $0{ }^{\circ} \mathrm{C}$, without the presence of further scarce substances that lower its cryogenic point. The size of the ice crystals also lowers the temperature at which crystals of different sizes crystallize due to the increase in free energy necessary to overcome surface tensions when a new interfacial surface is created. However, the formation of new ice crystals starting from the liquid phase implies the creation of a solid-liquid interfacial surface which requires an extra energy compared to the thermodynamic equilibrium. What corresponds to the temperature at which it is represented in the new crystals (in the absence of any solid phase, including impurities) is much lower than that of equilibrium the smaller the crystal. This phenomenon, explained by equation 2 , depends on free energy (on surface tension); since small crystals have more free energy than larger crystals, their freezing point is lower (Cook, Hartel, 2010).

$$
\Delta T_{c}=\frac{2 \sigma T_{\infty}}{\rho_{s} \Delta H_{f u s} r}
$$

In which:

$\sigma=$ surface tension

$\Delta$ Hfus $=$ latent heat of fusion

$\rho=$ density of the ice crystal

$\mathrm{r}=$ critical radius of the crystal

Nucleation described the birth of the crystal (Hartel, 2001). The nucleation of the ice crystals takes place starting from the freezing phase. The very small nuclei found on the internal walls of the batch freezer are scraped by the moving blades (or screws) and involve the site of the growth of the ice crystals.

The distribution of the typical size of the ice crystals inside the gelato is shown in Fig. 2.

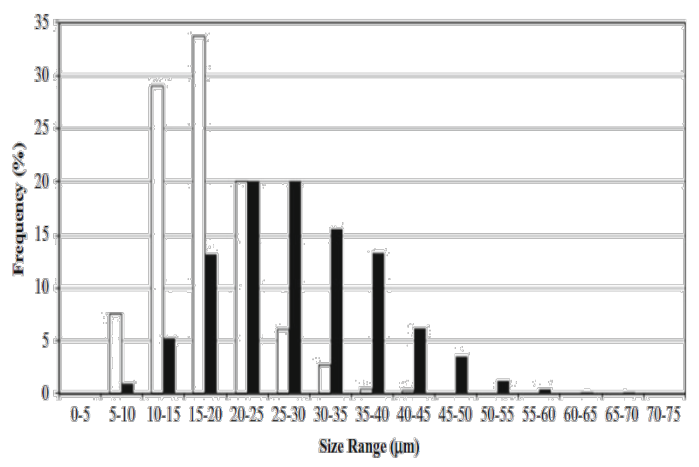

Figure 2. Frequency of distribution of ice crystals in gelato (Douglas, Hartel, 2013)

As can be seen from the graph, the ice crystals vary in size. The greatest distribution occurs between 10 and $25 \mu \mathrm{m}$ (immediately after the freezing phase, in white) and between 25 and 40 $\mu \mathrm{m}$ (after the temperature has been lowered, in black) (Douglas, Hartel 2013). After stable nuclei have formed they grow to form crystals. A fundamental ingredient of gelato is coffee, of which there are about 80 types of varieties (Grassia et al., 2019). The most common commercial varieties are only two: Coffea Arabica and Coffea Robusta. The quantity of these components inside the beans is variable and depends mainly on genetic aspects, the maturation to which they are subjected and the processing techniques (Vecchio et al., 2012). 
The chemical composition of green beans is made up of water, carbohydrates, fibers, proteins, amino acids, lipids, minerals, organic acids and caffeine (Tab. 1).

Table 1. Chemical composition of coffee (Chu, 2012)

\begin{tabular}{|l|c|}
\hline \multicolumn{2}{|c|}{ Carbohydrates and fibers } \\
\hline Components & Coffee' $^{\prime}(\mathbf{g} / \mathbf{1 0 0 g})$ \\
\hline Sugar & $6-9$ \\
\hline Polysaccharides & $34-44$ \\
\hline Lignin & 3 \\
\hline Pectin & 2 \\
\hline \multicolumn{2}{|c|}{ Nitrogen compounds } \\
\hline Components & Coffee'(g/100g) \\
\hline Protein & $10-11$ \\
\hline Caffeine & $0.9-1.3$ \\
\hline Lipid & $18.55-22.2$ \\
\hline Mineral & $5.5-9.3$ \\
\hline Water & 4.1 \\
\hline
\end{tabular}

Carbohydrates are precursors of Maillard's reactions. This reaction occurs during the roasting of green coffee beans. During this process, in fact, sugars combine with amino acids and represent a high number of high molecular weight components responsible for the color variation of coffee and some antioxidant properties (Thurston et al., 2013). The plot, created through sensory analysis.

\section{Results and discussions}

The first test was that of the artisan production of granita with the ice method and the sale with the instrument of the quantity of sale, the production of cold is more intense. Once the mixture was introduced into the carapine, the temperature was monitored, considering this as an important initial point. Temperature monitoring was detected in the ice, in the volume (internal surface of the carapina) and in the heart (center of the mixture) of the carapina attested by photographic image. Initially the mixture was rather dark as can be seen from Fig. 3.

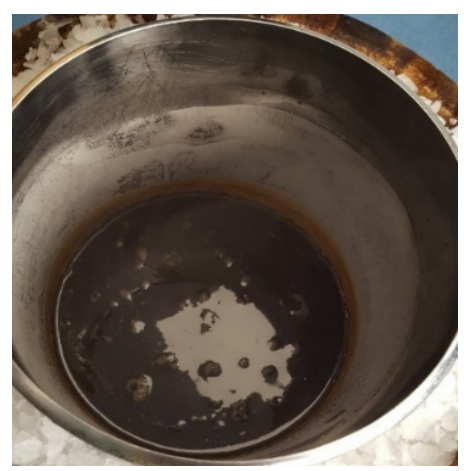

Figure 3. Mixture just introduced inside the carapina

After 35 minutes, the consistency and coloration of the roasted coffee is noted, as can be seen in Fig. 4.

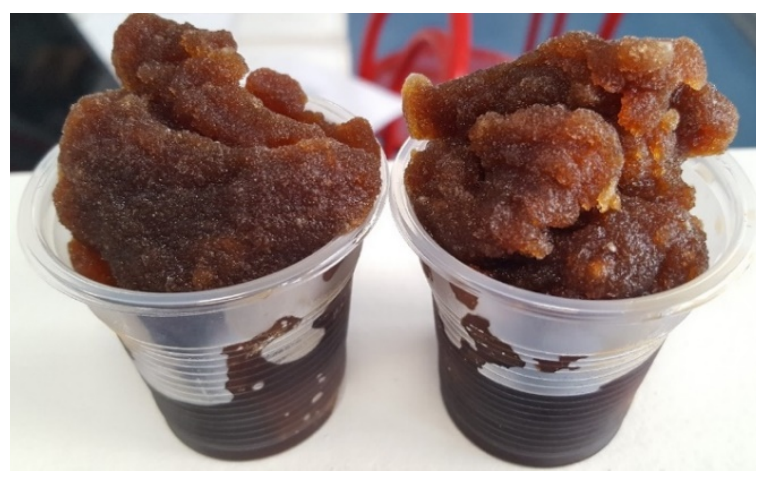

Figure 4. Coloring of the granita after 35 minutes

The texture, created by sensory analysis, the finish of the granita is excellent on the palate and very soft. As can be seen from Fig. 5 the resulting color is black, typical of freshly roasted coffee. The goal would be to report this result also in the production of sorbet, gelato and granita with an industrial machine.

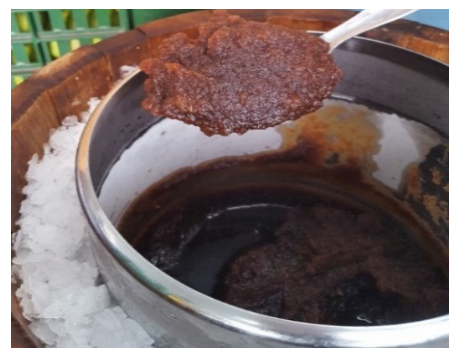

Figure 5. Coloring of the granita after 35 minutes 
In the following graph (Fig. 6) instead it is possible to notice the trend of the three temperatures with time.

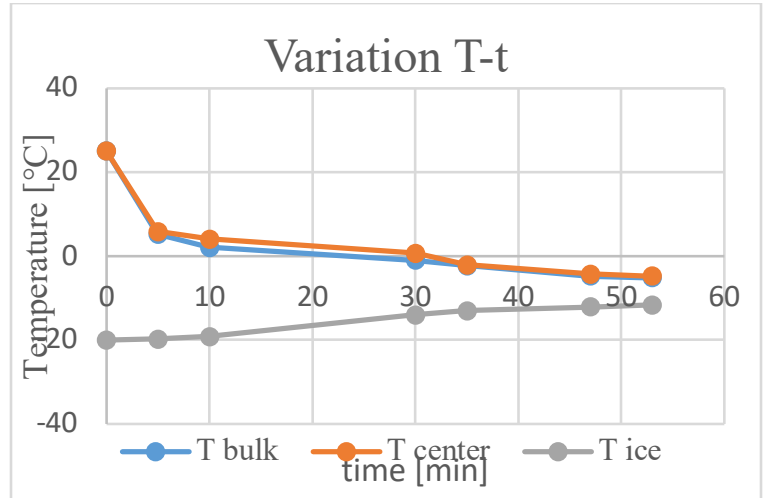

Figure 6. Variation of temperatures over time

The production of artisanal gelato with a horizontal batch freezer begins with the extraction of the coffee and the relative one with high pasteurization with cream. This step is necessary to reduce the bacterial load, but also to favor the melting of sugars and denature the proteins. Parallel to pasteurization, the homogenization of the phase in which the components are emulsified through the crushing of the fat globules also takes place. The output of the pasteurizer can be seen as the coffeecream-powder mixture has lost color. This is quite obvious due to the presence of the cream which acts as a "whitener" (Fig.7).

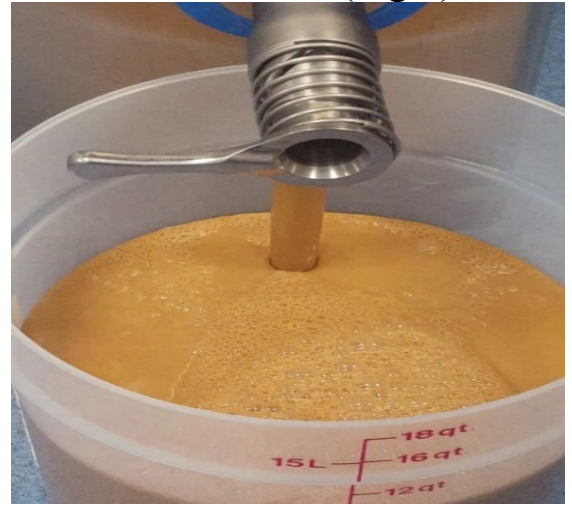

Figure 7. Cream-coffee-sugar mixture after pasteurization

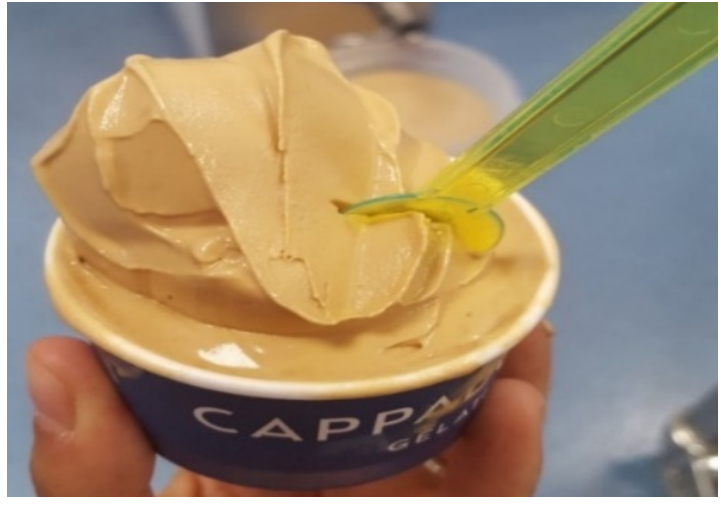

Figure 8. Representation of coffee gelato

At the exit of the batch freezer the coffee cream is clear (Fig. 8). The number of revolutions of the auger and of the feed pump has been changed. Note how the color is unchanged from before. The only change reported is to the texture of the gelato, as this is more "wet" and less delicate on the palate. The production of artisanal sorbet with a horizontal coffee batch freezer takes place, once the coffee is extracted, sugars and neutrals are added and mixed in order to obtain a homogeneous mixture. The final mixture will have the following composition by weight: $59 \%$ coffee, $39.7 \%$ sugars and fibers (inulin, chicory root extract), $0.3 \%$ neutral. At the exit of the batch freezer the texture is comparable to that of the coffee cream, although it is only a mixture containing coffee, sugars and neutrals. In Fig. 9 it is possible to notice the difference in color of the creamed coffee sorbet and the mixture of non-creamed liquid coffee.

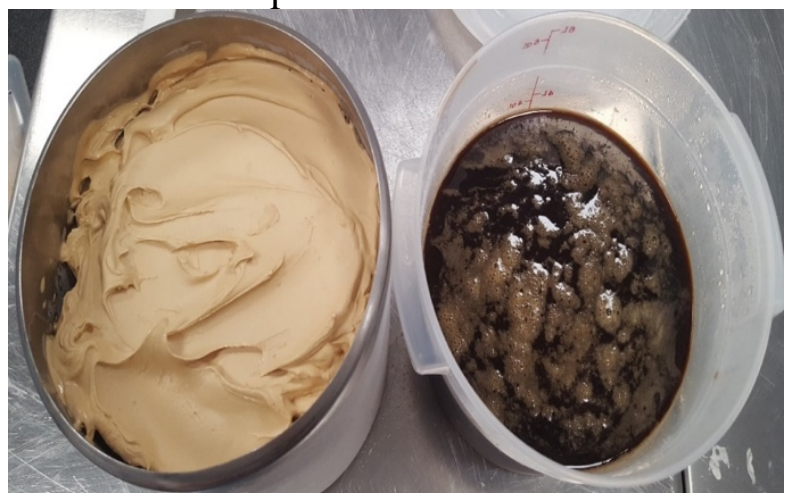

Figure 9. Color difference of the liquid mixture and the sorbet 


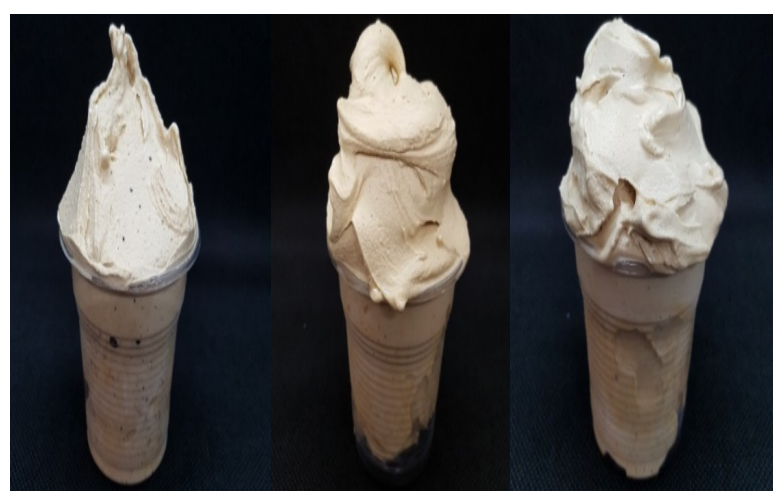

(a) (c)

Figure 10. Coffee sorbets with the addition of micronized coffee $30 \mu \mathrm{m}$ (a), $50 \mu \mathrm{m}$ (b), $100 \mu \mathrm{m}$ (c)

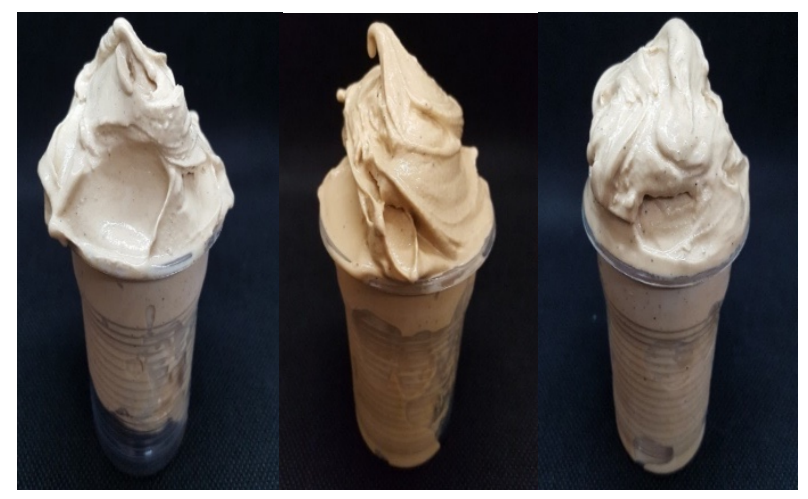

(a)

(b)

(c)

Figure 11. Coffee cream with the addition of micronized coffee $30 \mu \mathrm{m}$ (a), $50 \mu \mathrm{m}$ (b), $100 \mu \mathrm{m}$ (c)

Following the results obtained previously in the production of coffee granita, coffee milk cream and coffee sorbet, it is clear that the problem posed by the Cappadonia company actually arises. To be able to remedy this problem, it was thought to be able to add the micronized coffee inside the pre-certified mixture. For this reason, thanks to the collaboration with Morettino Caffè, in Palermo, it has been possible to obtain ground coffee with three different millings in order to carry out three distinct tests $(30 \mu \mathrm{m}, 50 \mu \mathrm{m}$ "Turkish coffee milling", $100 \mu \mathrm{m})$. Once the micronized coffee blend from Morettino is obtained, it is a procedure with the test of adding it to the coffee sorbet blends and pasteurized coffee creams,

before the batch freezing process. However, no particular differences have emerged from the addition of micronized coffee in the coffee sorbet (Fig. 10) and gelato (Fig. 11).

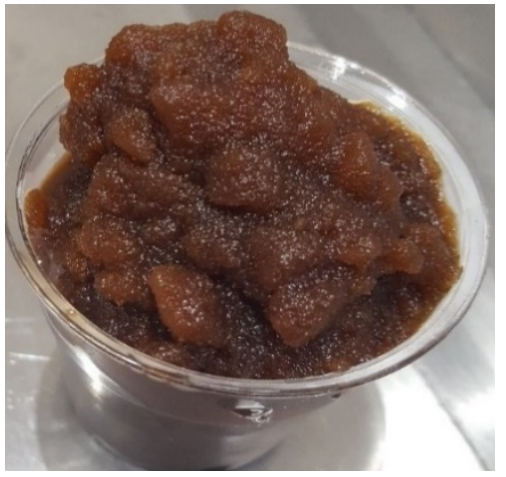

Figure 12. Production of coffee granita with granita machine

Following the tests carried out, the color variation in the production of granita was monitored with the slush machine. The production of the granita had previously been done with the hand-made ice and salt technique. Remembering the above test, the color that came out was quite dark tending to black. We would therefore expect that the production of the same granita, starting from the same matrix, will be the same by varying the means of production. By re-proposing the low speeds in the granite machine, note that the result is similar to that obtained with the ice and sale technique (Fig. 12).

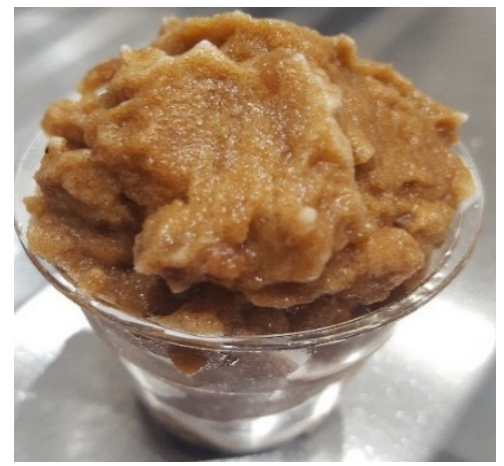

Figure 13. Texture of the granita as the number of turns increases 
By increasing the number of revolutions, reaching $80 \mathrm{rpm}$, the color of the granita changes to a hazelnut color (almost caramel color) (Fig. 13)

From the tests carried out, it is therefore deduced that the color is modified as the stirring speed changes, resulting increasingly clearer with increasing speed. at low speeds from low temperatures, while at higher speeds from high temperatures. This observation was confirmed by increasing the stirring speed. For this reason, it was decided to re-propose the high speeds in the production of granita with the ice and salt technique. The aim was to verify that the color change was not caused by a chemical phenomenon but by a physical phenomenon or correlated with the increase in speed. The final color, after 3 minutes it was hazel colored as you can see in Fig. 14. From this it can be seen how the monument to speed adversely affects the coloring of the final product.

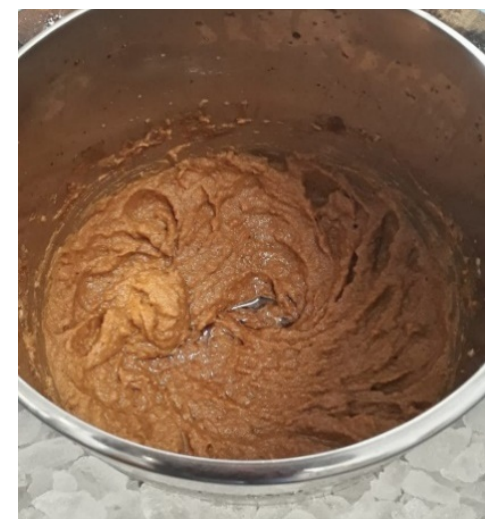

Figure 14. Color variation with increasing speed

The last test carried out on the coffee sorbet consisted in the production of it with the technique with ice and salt, at low and high speeds. It was expected, also for this test, that low speeds would improve the finished product, while high speeds would negatively affect the quality and coloring of the product. Indeed, this is what has been created. In this case too, in fact, at low stirring speeds (Fig. 15) it can be seen that the coloring is rather dark.

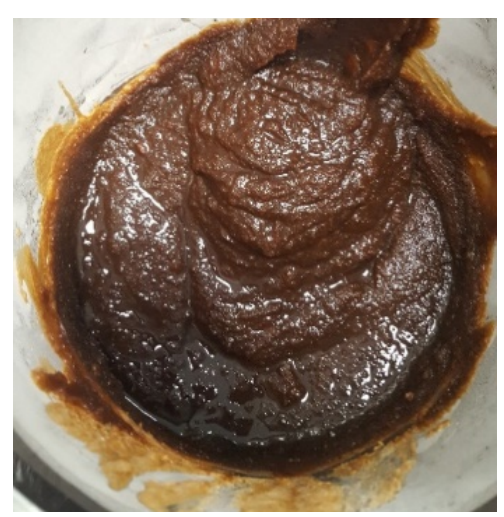

Figure 15. Color variation of the artisan sorbet

Increasing the speed you notice how already after a couple of minutes the color has both visibly changed. In fact, it is of a color similar to hazelnut (Fig. 16).

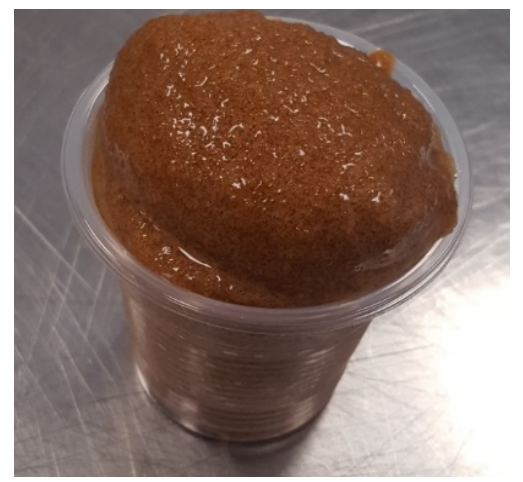

Figure 16.Coloring of the sorbet at high speeds

After 30 minutes from the end of the test, a change is noticed. The color of the hazelnut sorbet seemed to take on the original color again, that is, that of coffee (Fig. 17). This result shows that at low speeds, both for the granita and for the sorbet, the ice crystals, growing on a few nuclei, form large ice crystals reflecting the color of the mixture. The high speeds, for both preparations, instead break the large crystals and therefore they can no longer act as mirrors, effectively making the preparations lose their color. As you can see from the figure, the "hand" production also negatively affects the quantity of air incorporated by the product, the quantity of foam on the surface of the mixture is in fact quite high. 


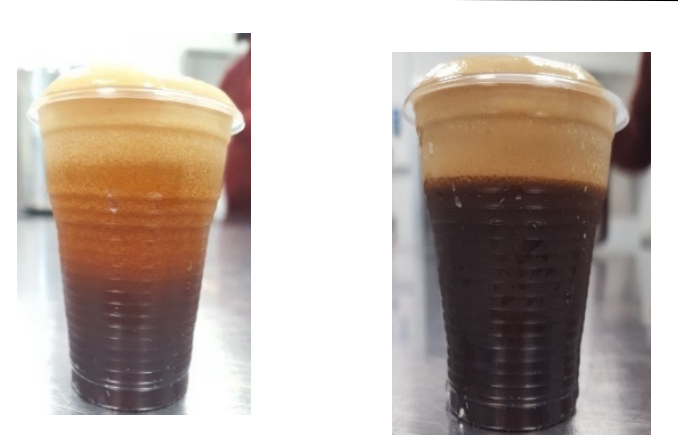

Figure 17. Melting of ice crystals and return to the original color

\section{Conclusions}

The production problem was to find a solution to the color variation in the sorbet and coffee granita. From the outset, the manifested problem apparently had the appearance of a chemical problem of a "chemical" nature. For this reason, the case study began with the search for which coffee molecule was negatively affecting the coloring of the finished product. Being both cold products, we paid attention to the ice crystals that were inevitably created during their production. At low speeds the ice crystals grew on a few nuclei creating rather large crystals, at high speeds, however, the crystals did not have time to grow on many nuclei, thus resulting rather small and invisible to the naked eye. The larger crystals, being clearly visible, reflected the dark color of the coffee, making both products appear "black". The smaller crystals, on the other hand, being invisible to the naked eye, did not reflect the color of the coffee, making the granita and sorbet appear "clear". This was demonstrated by melting products where high speeds had changed their color. Once the ice crystals were melted, the color turned dark again, confirming our results.

\section{References}

Belitz, H. D., Grosch, W, Schieberle, P. (2009). Food Chemistry, $4^{\text {th }}$ Edition, Springer.

Bordetto, M. (2018). Attorno al cibo Profili giuridici e sfide tecnologiche dello Smart Packaging in campo alimentare, Trento Law and Technology Research Group, Student Paper n. 39.
Caviezel, L. (2016) Scienza e tecnologia del gelato artigianale, Chirotti editori.

Chu, Y. (2012). Coffee: Emerging Health Effects and Disease Prevention, $1^{\text {st }}$ Edition, Wiley-Blackwell.

Clarke, C. (2004). The Science of ice cream, RSC.

Cook, K.L.K., Hartel, R.W. (2010) Mechanisms of Ice Crystallization in Ice Cream Production, Comprehensive Reviews in food science and food safety, Vol.9, 213222.

Corvitto, A.(2005). I segreti del gelato, il gelato senza segreti, Vilbo group.

Douglas, G. H., Hartel, R. W. (2013). Ice cream, 7th Edition, Springer.

Eisner, M.D., Wildmosera, H., Windhaba, E. J. (2005). Air cell microstructuring in a high viscous ice cream matrix, Colloids and Surfaces. Physicochemical and Engineering Aspects, 390-399.

Flores, A.A, Goff, H.D. (1999). Recrystallization in ice cream after constant and cycling temperature storage conditions as affected by stabilizers. Journal of Dairy Science, 1408-1415.

Grassia, M., Salvatori, M., Roberti, M., Planeta, D., Cinquanta, L. (2019). Polyphenols, methylxanthines, fatty acids and minerals in cocoa beans and cocoa products, Journal of Food Measurement and Characterization Vol. 13 (3), 1721-1728

Hartel, R.W. (1996). Ice crystallization during the manufacture of ice cream, Food Science \& Technology, Vol.7.

Hartel, R. W. (2001) Crystallization in foods, Aspen Publishers, 325.

Leducq, D., NDoye, F.T., Alvarez, G. (2014). Phase change material for the thermal protection of ice cream during storage and transportation, Refrigeration Process Engineering,133-139.

McCabe, W. L., Smith, J.C., Harriotmt, P. (2005) Unit operations of chemical engineering, 7th edition, McGraw-Hill.

Soukoulis, C., Fisk, I. D. and Bohn, T. (2014). Ice Cream as a Vehicle for Incorporating Health- romoting Ingredients: 
Conceptualization and Overview of Quality and Storage Stability, Comprehensive reviews in food science and food safety, Vol.13.

Syed, Q.A., Anwar, S., Shukat, R. et al. (2018). Effects of different ingredients on texture of ice cream. Journal of Nutritional Health \& Food Engineering, 8 (6), 422-435.

Thurston, R. W., Morris, J, Steiman, S. (2013). Coffee A Comprehensive Guide to the Bean, Beverage, and the Industry, Rowman \& Littlefield.

Tolley, A. S. (2014). Consumption, Side effect and Impact on Performance and Mood, Nova Science Publishers, Inc., 2014

Van Boekel, M. A. J. S. (2006). Formation of flavour compounds in the Maillard reaction, Biotechnology Advances (24), 230 - 233.

Vecchio, A., Mineo, V., Planeta, D. (2012). Ochratoxin A in instant coffee in Italy. Food Control, 28 (28), 220-223.

\section{Acknowledgment}

Thanks to Caffè Morettino Srl of Palermo, Gelateria Cappadonia and in particular Dott. Donato Didonna Managing Director Cappadonia Srl, Eng. Tiziana Di Pasquale Operations manager and Master gelato maker Antonio Cappadonia. 